\title{
MULTISPECIES AND MONOCULTURE RHIZOREMEDIATION OF POLYCYCLIC AROMATIC HYDROCARBONS (PAHS) FROM THE SOIL
}

\author{
Mphekgo P. Maila, P. Randima \& Thomas E. Cloete
}

\section{INTRODUCTION}

Phytoremediation, the use of plants and associated microorganisms to degrade or immobilize contaminants in soil and groundwater, is increasingly being considered for rehabilitating moderately contaminated soils. This technology represents a potential low-cost, effective, and low-maintenance alternative for waste management (Aprill and Sims, 1990). The mechanisms of phytoremediation for hazardous organic contamination in soil include, direct plant uptake, microbial degradation stimulated by plant roots, cometabolism of contaminants in the rhizosphere and adsorption to humic or organic matter (Chen et al., 2003; Cunningham and Ow, 1996; Schnoor et al., 1995).

Laboratory and greenhouse experiments on plant-mediated dissipation of polycyclic aromatic hydrocarbons (PAHs) have concentrated mainly on the use of monoculture rhizoremediation of PAHs from the soil (Aprill and Sims, 1990; Günther et al., 1996; Lee and Banks, 1993; Reilly et al., 1996; Walton et al., 1994). In these studies, the extent of organic pollutant removal in planted soil has been significantly greater than in nonplanted soil. However, the information about the effectiveness of multispecies rhizoremediation of PAHs is lacking. The use of soil microcosms with mixed planted species has the potential to increase soil heterogeneity (Angers and Caron, 1998) and microbial diversity, which can improve the microbial competence of the soil bacteria for effective pollutant removal.

In this study, we evaluated the effectiveness of both monoculture rhizoremediation and multispecies rhizoremediation of PAH-contaminated soil. In addition, we evaluated the functional diversity of the PAH-contaminated and noncontaminated rhizosphere and nonrhizosphere soil using community-level physiological profiles.

\section{MATERIALS AND METHODS}

\section{A. Chemicals}

All solvents (dichloromethane 99\% and trichloromethane 99\%) and PAH (Naphthalene $98 \%$, fluorene $98 \%$, and pyrene $98 \%$ ) were purchased from Sigma-Aldrich, South Africa.

\section{B. Soil}

The predominantly sandy loam soil used in the experiments was taken from the Pretoria Campus of the Council of Scientific and Industrial Research (CSIR), South Africa. The artificial contamination of the soil with PAH was done as described by Leyval and Binet (1998). The PAHs 
were first dissolved in trichloromethane before being mixed with $1 \%$ of the total soil to be polluted. Trichloromethane was allowed to volatilize under fumehood and the amended soil was mixed thoroughly with the remaining $99 \%$ of the soil. After mixing, three samples of the artificially contaminated soil were collected in sealable glass containers for PAHs analysis. The concentration of the individual PAHs in the soil averaged $300 \mathrm{mg} / \mathrm{kg}$ soil. Further soil sampling and storage of the rhizosphere and nonrhizosphere soil in the experiments were done as described by Wollum (1982). The rhizosphere soil (soil that adheres to the roots) was collected in sterile bags by gently shaking loose soil from the intermingled roots of the planted treatments. This rhizosphere soil was used for determining the community-level physiological profiles and for PAH analysis. The nonrhizosphere soil was collected from the pots and mixed thoroughly before further analysis. Analyses were made within $24 \mathrm{~h}$ of sampling. However, in cases were this was not feasible, the soil samples where stored overnight at $4^{\circ} \mathrm{C}$.

\section{Plants}

The seeds of Brachiaria serrata (Velvet signal grass) were bought from Agricol Pty Ltd, South Africa, and those of Eleusine coracana (African millet) were obtained from Plant Genetic Resources Directorate (Agriculture Department, South Africa). B. serrata is a perennial tufted grass with shrub-like growth form. E. coracana is a robust annual tufted grass with slated culms and has an exceptionally dense and strong root system. The grass seeds were sown in trays (38 $\mathrm{cm} \times 38 \mathrm{~cm}$ ) containing the soil. The trays were incubated at room temperature in the greenhouse with natural day-night cycles until germination of both plant seeds occurred. No supplemental lighting was supplied. However, the average natural cycle was $9 \mathrm{~h}$ of daylight. The room temperature in the greenhouse averaged $28^{\circ} \mathrm{C}$ during the period of incubation. The grass seedlings were used in the phytoremediation experiment (vegetated microcosms).

\section{Vegetated and Nonvegetated Microcosms}

Plants mediated removal of PAH was evaluated using monoplanted and multiplanted soil microcosms. The soil was artificially contaminated with PAHs as described above. The concentration of each PAH in the soil was $300 \mathrm{mg} / \mathrm{kg}$ soil. This "time zero" concentration is the average of the individual PAHs detected. The monoplanted and multiplanted treatments were prepared as shown in Table 1. Six hundred grams of each soil preparation (Table 1) were placed in $10-\mathrm{cm}$ pots with saucers for leachate collection. The grass seedlings were planted in different pots as shown in Table 1. The density of the plants was one plant per pot for the monocultured treatments, while two plants (as shown in Table 1) were used for the multispecies treatment. The pots were placed in the greenhouse at room temperature and natural day-night cycles. No supplemental lighting was supplied. However, the average natural cycle was $9 \mathrm{~h}$ of daylight. The room temperature in the greenhouse averaged $28^{\circ} \mathrm{C}$ during the period of incubation. Two hundred millilitres of water was used to water the plants every $2 \mathrm{~d}$. In instances where leachates were produced, the leachate was used to water the same pots. Each treatment had 11 pots and 2 pots for each treatment were sacrificed after 2, 6, and $10 \mathrm{wk}$ of incubation to determine concentrations of PAHs in the soil. ANOVA (Analysis of Variance) was used to determine the difference between the treatments.

\section{E Chemical Analysis}

Residual PAH in treatments T0-T3 were quantified as described by Maila and Cloete (2002). PAHs were extracted from $25 \mathrm{~g}$ soil of each treatment using dichloromethane. PAHs were quantified after extraction with dichloromethane, using a Varian Saturn 2000 Ion Trap Gas 
Chromatography/Mass Spectrometer equipped with a Chrompack CP-SIL 8CB-MS (5\% phenyl) Fused Silica Capillary Column $(30 \mathrm{~m} * 0.25 \mathrm{~mm} * 0.25 / \mathrm{zm})$. The detector was tuned according to EPA $8270 \mathrm{C}$ using DFTPP. Injector temperature was $230^{\circ} \mathrm{C}$, oven temperature program: $30^{\circ} \mathrm{C}(6$ $\min ), 10^{\circ} \mathrm{C} / \mathrm{min}, 300^{\circ} \mathrm{C}(7 \mathrm{~min})$. Analyses were done in triplicate.

Table 1 Treatments used in the experiments

\begin{tabular}{ll}
\hline Treatments & \multicolumn{1}{c}{ Additions/Preparations } \\
\hline T0 (Control) & Soil + PAHs \\
T1 (CSEC) & Soil + PAHs + E.corocana \\
T2 (CSBS) & Soil + PAHs + B.serrata \\
T3 (CSBSEC) & Soil + PAHs + E.corocana + B.serrata \\
T4 (UCS) & Soil \\
T5 (UCSEC) & Soil + E.corocana \\
T6 (UCSBSEC) & Soil \pm B.serrata \pm E.corocana \\
\hline
\end{tabular}

\section{F. Community-Level Physiological Profiles (CLPPs)}

The microbial community level physiological profiles of the different treatments shown in Table 1 was done using the soil samples sacrificed after 4 wk of incubation. This period was deemed to be sufficient to allow the acclimatisation of the plants in the contaminated and noncontaminated soils. In addition, the PAH dissipation analysis were also done (as described above) using the samples sacrificed after 4 wk of incubation (week 4 PAH dissipation results not included). For CLPP determination, three pots per treatment were used. The rhizosphere and nonrhizosphere soils were sampled as described above and microbial suspensions were prepared from the soil for Biolog ${ }^{\mathrm{TM}}$ inoculation as described by Wünsche et. a/. (1995). Ten grams of soil and $100 \mathrm{ml}$ of $0.2 \%$ tetra-sodium pyrophosphate solution were shaken in an Erlenmeyer flask for $30 \mathrm{~min}$. on a rotary shaker at $140 \mathrm{rpm}$. The mixture was allowed to settle for $5 \mathrm{~min}$. and the supernatant used for serial dilutions in a physiological saline solution. After appropriate dilutions in sterile saline solution, the cell suspensions were used to determine the number of culturable heterotrophs and to inoculate BIOLOG ${ }^{\mathrm{TM}}$ GN micro plates. The number of culturable heterotrophs (results not included), expressed as CFU, was determined by spreading $0.1 m \boldsymbol{f}$ cell suspension on to a nutrient agar (Biolab Diagnostics Pty Ltd., South Africa) medium, amended with cycloheximide $(200 \mu \mathrm{g} / \mathrm{ml})$ to suppress fungal growth. Plate counting was done in triplicate and incubation was at $28^{\circ} \mathrm{C}$ for $24 \mathrm{~h}$. Dilutions giving the same number of culturable heterotrophs were used for Biolog ${ }^{\mathrm{TM}}$ inoculation.

To obtain the metabolic fingerprints of the microbial communities in different treatments (Table 1), three replicate (three pots per treatment) of all the soil extracts were inoculated in BIOLOG $^{\mathrm{TM}}$ GN microtiter plates (Biolog Inc., Hayward, CA) containing 95 different sole-carbon sources and a control without a carbon source. $100 \mu \mathrm{L}$ of each soil extract was added to each well. The BIOLOG ${ }^{\mathrm{TM}} \mathrm{GN}$ plates were incubated at $28^{\circ} \mathrm{C}$ and readings done using a Bio-Tek Elx 800 (Bio-Tek Instruments Inc., IL, USA) micro plate reader at $600 \mathrm{~nm}$ after 24,48, and $72 \mathrm{~h}$. Statistical analyses were done using STATISTICA for Windows release 5.1.

\section{RESULTS}

Plant-mediated PAH dissipation was evaluated using monoplanted and multiplanted soil microcosms. PAH dissipation was higher in the planted soils compared to the nonplanted soil (Tables 2-4). There was, on average, a 97\% reduction of naphthalene in planted soils compared 
to $63 \%$ in the nonplanted soil. The dissipation of naphthalene and fluorene was higher in the multiplanted soil compared to the monoplanted and nonplanted soil (Tables 2 and 3). The concentration of naphthalene was undetectable in the multiplanted treatment compared to $96 \%$ reduction in the monoplanted treatments and 63\% reduction in the non-planted control after $10 \mathrm{wk}$ of incubation. There was a $96 \%$ reduction in fluorene from the multiplanted treatment compared to $81 \%$ reduction in the monoplanted treatment with E. corocana and $47 \%$ of the control

Table 2 Naphthalene concentrations ( $\mathrm{mg} / \mathrm{kg}$ soil) in monocultured and multiplanted soil treatments (average \pm std. dev)

\begin{tabular}{lrrrr}
\hline Weeks of Incubation & Control (T0) & CSEC (T1) & CSBS (T2) & CSECBS (T3) \\
\hline 2 & $293 \pm 0.632$ & $224 \pm 0.089$ & $202 \pm 1.032$ & $198 \pm 0.019$ \\
6 & $248 \pm 0.059$ & $110 \pm 1.112$ & $98 \pm 0.221$ & $66 \pm 1.532$ \\
10 & $111 \pm 0.632$ & $12 \pm 0.321$ & $9 \pm 1.209$ & 0 \\
\hline
\end{tabular}

Table 3 Fluorene concentrations ( $\mathrm{mg} / \mathrm{kg}$ soil) in monocultured and multiplanted soil treatments (average \pm std. dev)

\begin{tabular}{lrrrr}
\hline Weeks of Incubation & Control (T0) & CSEC (T1) & CSBS (T2) & CSECBS (T3) \\
\hline 2 & $296 \pm 0.089$ & $241 \pm 0.087$ & $246 \pm 0.009$ & $236 \pm 0.127$ \\
6 & $235 \pm 0.635$ & $178 \pm 1.612$ & $164 \pm 0.112$ & $110 \pm 0.255$ \\
10 & $160 \pm 1.541$ & $56 \pm 0.065$ & $38 \pm 2.872$ & $10 \pm 1.432$ \\
\hline
\end{tabular}

treatment. However, there was no significant difference $(\mathrm{P}<0.01)$ in the dissipation of pyrene in both the mono- and multiplanted treatments (Table 4). There also was no significant difference between the dissipation of PAHs in the treatment with Brachiaria serrata and the treatment with Eleusine corocana (Tables 2-4).

As the development of microbial communities inhabiting the root zone is influenced by plant species, it was expected that the dissipation of PAHs in treatments vegetated by different plant species would be different. However, this was not observed, as there was no significant difference $(\mathrm{P}<0.01)$ in $\mathrm{PAH}$ dissipation in treatments with $B$. serrata $(\mathrm{T} 2)$ and treatment with E. corocana $(\mathrm{T} 1)$.

In addition, as plants have the potential to increase soil heterogeneity and soil microbial diversities, it was expected that the treatment with "multiplants" would have a higher PAH dissipation compared to monoplanted (T1 and T2) treatments. This was observed as both naphthalene and fluorene dissipation was significantly higher $(\mathrm{p}<0.05)$ in the multiplanted treatments compared to the monoplanted treatments. However, different results were obtained for pyrene degradation.

\section{CLPPs}

Heterotrophic microbial communities were evaluated during phytoremediation of the PAHs by determining the metabolic fingerprints of the different treatments. Biolog plates with 95 different substrates were used to determine the community level physiological profiles of the different treatments. Both principle component analysis PCA and cluster analysis were used to evaluate the difference in substrate utilization patterns of the different 
treatments. PCA was performed to characterize the correlation between treatments, taking into account the absorbance values for all 96-response wells. Two principal factors were isolated from the individual patterns (Figure 1), which explained $63 \%$ of the variation. For the samples, factor one was related to the absorbance values for the wells, while factor 2 was related to the incubation time.

The metabolic fingerprints of the PAH-contaminated soils (CS, CSBS, CSBSEC, CSEC) were not closely related to the metabolic fingerprints of the noncontaminated soils, (UCS, UCSEC, UCBSEC; Figure 1). The metabolic fingerprint of the PAH-contaminated soil (CS) was more closely related to the contaminated monoplanted treatment with Brachiaria serrata (CSBS) and contaminated multiplanted soil with Brachiaria serrata and Eleusine corocana (CSBSEC) than to other treatments (Figure 1). The uncontaminated

Table 4 Pyrene concentrations ( $\mathrm{mg} / \mathrm{kg}$ soil) in monocultured and multiplanted soil treatments (average \pm std. Dev)

\begin{tabular}{lcccr}
\hline $\begin{array}{l}\text { Weeks of } \\
\text { Incubation }\end{array}$ & Control (T0) & CSEC (T1) & CSBS (T2) & CSECBS (T3) \\
\hline 2 & $298 \pm 0.283$ & $262 \pm 0.064$ & $258 \pm 0.832$ & $261 \pm 0.432$ \\
6 & $266 \pm 0.642$ & $203 \pm 1.412$ & $218 \pm 1.414$ & $198 \pm 0.432$ \\
10 & $255 \pm 0.565$ & $166 \pm 1.632$ & $128 \pm 0.876$ & $117 \pm 1.555$ \\
\hline
\end{tabular}

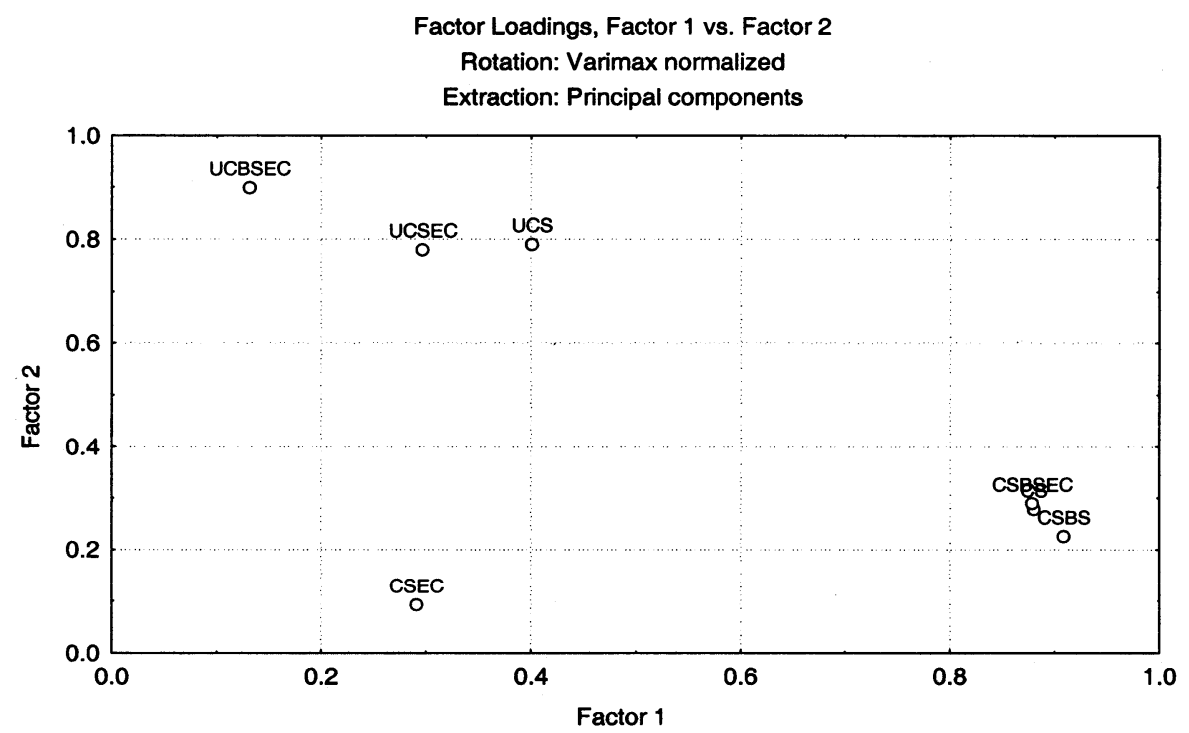

Figure 1 Metabolic diversity of PAH-contaminated and noncontaminated rhizosphere and nonrhizosphere soils. UCSuncontaminated soil, CS — contaminated soil, CSBS — contaminated soil with Brachiaria serrata, UCSEC-Uncontaminated soil with Eleusine corocana, UCBSEC - uncontaminated soil with Brachiaria serrata and Eleu-sine corocana, CSBSECcontaminated soil with Brachiaria serrata and Eleusine corocana.

soils were more "closely" related to each other than to the PAH-contaminated soils. 
The metabolic fingerprints of the different treatments were further evaluated using hierarchical clustering (Figure 2). In a dendrogram, the contaminated soils (CS, CSBS, and CSBEC) were clustered together while CSEC was clustered with the uncontaminated soils. Both PCA and cluster analysis indicated that the metabolic fingerprints of PAH contaminated soils (with the exception of CSEC) were closely related, as were the metabolic fingerprints of the uncontaminated soils.

As plants have the potential to increase soil heterogeneity and possibly soil diversity, it was expected that treatments with more plants will have high microbial competence, reflected by higher PAH dissipation and higher number of Biolog substrates (Tables 5 and 6) used by the multiplanted treatments compared to monoplanted treatments. Higher PAH dissipation was only evident with naphthalene and fluorene (Tables 2 and 3), while there was no significant difference in the amount of Biolog substrates (Table 6) used by the multiplanted and monoplanted contaminated treatments after $72 \mathrm{~h}$ of incubation. However, more Biolog substrates were used by microorganisms in the planted treatments compared to the nonplanted treatments (Table 6).

\section{DISCUSSIONS AND CONCLUSION}

This study investigates plant-mediated PAH dissipation using monoplanted and multiplanted soil microcosms. PAH dissipation was higher in the planted soils compared to
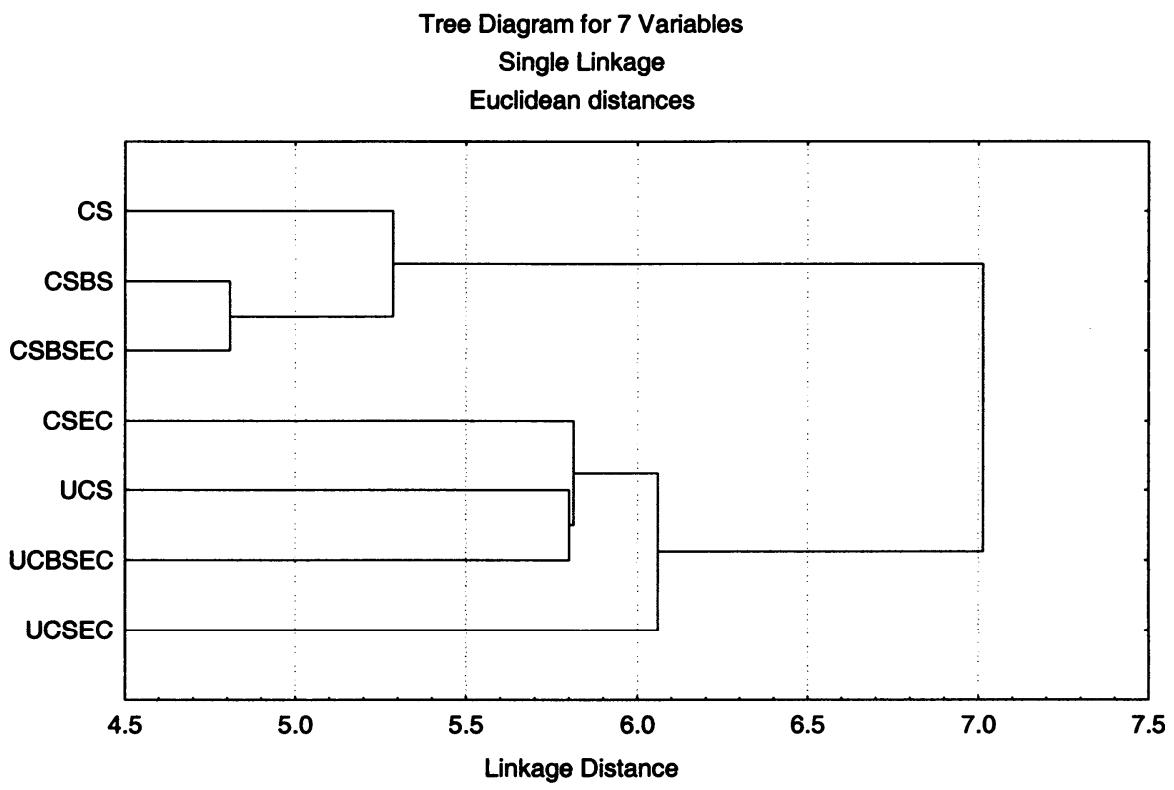

Figure 2 Cluster analysis of the PAH-contaminated and noncontaminated rhizosphere and nonrhizosphere soils.

the nonplanted control soil. This finding was in line with other findings, which indicated enhanced PAHs dissipation in vegetated soils compared to nonvegetated soil (Aprill and Sims, 1990; Reilly et al., 1996). According to Muratova et al. (2003), significant PAH dissipation is attained in the vegetated soils as plants stimulate the rhizosphere micro flora, which degrade the pollutants. 
The dissipation of naphthalene and fluorene was higher in the multiplanted soil compared to the monoplanted and nonplanted control soil. However, there was no significant difference in the dissipation of pyrene in the mono- and multiplanted treatment. This was not surprising, as the rate of $\mathrm{PAH}$ degradation is inversely proportional to the number of rings in the PAH molecule (Cerniglia, 1992; Cerniglia and Heitkamp, 1989). In addition, the duration of incubation was probably not sufficient for the complete dissipation of pyrene in both treatments or the lack of pyrene biodegraders was responsible for this difference.

There was also no significant difference between the dissipation of PAHs in the treatment with Brachiaria serrata and the treatment with Eleusine corocana. As plant species influence the development of microbial communities inhabiting the root zone (Rovira, 1956, 1959), it was expected that the dissipation of PAHs in treatments vegetated by different plant species will be different. This expectation emanated from the fact that the two grasses have slightly different root structure and also due to the probable difference in the root exudates, which may influence the "competency" of the rhizosphere microbial community inhabiting the plants. However, this was not realized, as there was no significant difference in PAH dissipation between treatments with B. serrata and treatment with E. corocana. This finding was in contrast to findings by Muratova et al. (2003), who reported differences in the degradation of PAH with different plant species. However, alfalfa and reed species were used in their study, while different grass species were used in this study.

The data on enhanced dissipation of both naphthalene and fluorene in multiplanted treatments compared to monoplanted treatments suggests that phytoremediation can be enhanced by "bioaugumenting" moderately contaminated soil with multiplants instead of monocultures. 
Table 5 Carbon sources in biolog GN microplates

Biolog carbon sources

\begin{tabular}{|c|c|c|}
\hline Carboxylic acids & Amino acids & Carbohydrates \\
\hline Propionic acid & D-Alanine & D-Fructose \\
\hline Quinic acid & L-Alanine & D-Fucose \\
\hline D-Saccharic acid & L-Alanyl-Glycine & D-Galactose \\
\hline Sebacic acid & D-Serine & Gentiobiose \\
\hline Succinic acid & L-Serine2 & $\alpha$-D-Glucose \\
\hline Acetic acid & L-Threonine & m-Inositol \\
\hline Cis-Aconitic acid & D,L-Carnitine & $\alpha$-Lactose \\
\hline Citric acid & L-Asparagine & N-Acetyl-D-galactosamine \\
\hline Formic acid & L-Aspartic acid & N-Acetyl-D-glucosamine \\
\hline D-Galactonic acid lactone & L-Glutamic acid & Adonitol \\
\hline D-Galacturonic acid & Glycyl-L-Aspartic acid & L-Arabinose \\
\hline D-Gluconic acid & Glycyl-L-glutamic acid & D-Arabitol \\
\hline D-Glucosaminic acid & L-Histidine & Cellobiose \\
\hline D-Glucoronic acid & Hydroxy-L-proline & $i$-Erythritol \\
\hline$\alpha$-Hydroxybutyric acid & L-Leucine & Lactulose \\
\hline$\beta$-Hydroxybutyric acid & L-Ornithine & Maltose \\
\hline$\gamma$-Hydroxybutyric acid & L-Phenylalanine & D-Mannitol \\
\hline$\rho$-Hydroxyphenylacetic acid & L-Proline & D-Mannose \\
\hline Itaconic acid & L-Pyroglutamic acid & D-Melibiose \\
\hline$\alpha$-Ketobutyric acid & $\gamma$-Aminobutyric acid & $\beta$-Methylglucoside \\
\hline$\alpha$-Ketoglutaric acid & Amines & Psicose \\
\hline$\alpha$-Ketovaleric acid & Phenylethylalamine & D-Raffinose \\
\hline D,L-Lactic acid & 2-Aminoethanol & L-Rhamnose \\
\hline Malonic acid & Putrescine & D-Sorbitol \\
\hline Phosphorylated chemicals & Aromatic chemicals & Sucrose \\
\hline Glucose-1-phosphate Glucose- & Inosine Urocanic acid & D-Trehalose \\
\hline 6-phosphate & Thymidine Uridine & Turanose \\
\hline D,L- $\alpha$-Glycerol phosphate & Brominated chemicals & Xylitol \\
\hline Alcohols & Bromosuccinic acid & Polymers \\
\hline 2,3-Butanediol Glycerol & & Dextrin Glycogen \\
\hline Amides & & $\alpha$-Cylcodextrin \\
\hline Succinamic acid & & Tween 80 \\
\hline Glucoranimide & & Tween 40 \\
\hline \multirow[t]{3}{*}{ Alaninamide } & & Esters \\
\hline & & Mono-methylsuccinate \\
\hline & & Methylpyruvate \\
\hline
\end{tabular}

However, as many organisms are known to produce toxins designed to minimize competition (Curl and Truelove, 1986), plants that are able to coexist or the so-called co-occurring plants should be evaluated for their potential to enhance rhizoremediation of PAHs. Also, longer-term studies should be considered to corroborate these results.

The metabolic fingerprints of the PAH-contaminated soils were different from the metabolic fingerprints of the noncontaminated soils. This can be attributed to the change in microbial diversity due to the presence of PAH. The availability of hydrophobic pollutants has been reported to cause significant changes in soil microbial communities (Saxton and Atlas, 1977; Atlas et al., 1991; Wünsche et al., 1995). The metabolic fingerprint of the PAH-contaminated soil was more closely related to the contaminated monoplanted treatment with Brachiaria serrata and 
Table 6 Number of carbon sources that were not used by microorganisms in the different treatments ("total number of substrates used)

\begin{tabular}{|c|c|c|c|c|c|c|}
\hline Treatment $0(\mathrm{TO}) * 54$ & reatment $1(\mathrm{Tl}) * 80$ & reatment $2(\mathrm{~T} 2) * 75$ & Treatment $3(\mathrm{~T} 3) * 76$ & reatment $4(\mathrm{~T} 4) * 60$ & Treatment $5(\mathrm{~T} 5) * 77$ & Treatment $6(\mathrm{~T} 6) * 67$ \\
\hline $\begin{array}{l}\text { Carbohydrates } \\
\text { Adonitol, L-Arabinose, } \\
\text { L-Fucose, Gentiobiose, } \\
\alpha \text {-D-Lactose, } \\
\alpha \text {-D-Lactose, } \\
\text { D-Melibiose, } \beta \text { Methyl } \\
\text { D-Glucoside Carboxylic } \\
\text { acids Acetic acid, } \\
\text { cis-Aconitic acid, } \\
\text { D-Galactonic acid } \\
\text { Lactone, } \\
\text { D-Galacturonic acid, } \\
\text { D-Glucosaminic acid, } \alpha \\
\text { Hydroxybutyric acid, } \alpha \\
\text { Keto butyric acid, } \\
\text { Quinic acid, Succinic } \\
\text { acid } \\
\text { Amino acids } \\
\text { L-Alanine, L-Alanyl } \\
\text { glycine, L-Asparagine, } \\
\text { L-Aspartic acid, } \\
\text { L-Glutamic acid, Glycyl } \\
\text { L-Aspartic acid, Glycyl } \\
\text { L-Glutamic acid, } \\
\text { L-Ornithine, } \\
\text { L-Threonine, D-Serine, } \\
\gamma \text { Amino Butyric acid }\end{array}$ & $\begin{array}{l}\text { Carbohydrates } \\
\text { N-Acetyl } \\
\text { Galactosamine, } \\
\text { D-Arabitol, Turanose, } \\
\text { Xylitol } \\
\text { Carboxylic acids } \\
\text { cis-Aconitic acid, } \\
\text { p-Hydroxy phenylacetic } \\
\text { acid, } \alpha \text {-Keto valeric acid } \\
\text { Amino acids } \\
\text { L-Aspartic acid, } \\
\text { L-Phenylalanine, } \\
\text { L-Proline } \\
\text { Aromatic chemicals } \\
\text { Urocanic acid, Inosine, } \\
\text { Thymidine } \\
\text { Amides } \\
\text { Glucuronamide } \\
\text { Brominated chemicals } \\
\text { Bromosuccinic acid }\end{array}$ & $\begin{array}{l}\text { Carbohydrates } \\
\text { Adonitol, } \alpha \text {-D-Lactose, } \\
\beta \text { Methyl D-Glucoside } \\
\text { Carboxylic acids } \\
\alpha \text { Hydroxybutyric acid, } \\
\alpha \text { Keto butyric acid, } \\
\text { Quinic acid, Succinic } \\
\text { acid } \\
\text { Amino acids } \\
\text { L-Aspartic acid, } \\
\text { L-Glutamic acid, Glycyl } \\
\text { L-Aspartic acid, Glycyl } \\
\text { L-Aspartic acid, } \\
\text { L-Ornithine, } \\
\text { L-Threonine, } \gamma \text { Amino } \\
\text { Butyric acid } \\
\text { Phosphorylated } \\
\text { chemicals } \\
\alpha, D-G l u c o s e-1- \\
\text { Phosphate, } \\
\text { D-Glucose-6-Phosphate } \\
\text { Polymers } \\
\text { Dextrin, Tween } 40 \\
\text { Esters } \\
\text { Succinic acid } \\
\text { monomethyl esther } \\
\text { Amines } \\
\text { Putrescine }\end{array}$ & $\begin{array}{l}\text { Carbohydrates } \\
\text { Adonitol, } \beta \text { Methyl D } \\
\text { Glucoside } \\
\text { Carboxylic acids } \\
\alpha \text {-Hydroxybutyric acid, } \\
\alpha \text { Keto butyric acid, } \\
\text { Quinic acid, Succinic } \\
\text { acid } \\
\text { Amino acids } \\
\text { L-Aspartic acid, Glycyl } \\
\text { L-Glutamic acid, } \\
\text { L-Ornithine, } \\
\text { L-Phenylalanine, } \\
\text { L-Threonine, } \gamma \text { Amino } \\
\text { Butyric acid } \\
\text { Phosphorylated } \\
\quad \text { chemicals } \\
\alpha, \text { D-Glucose-1- } \\
\text { Phosphate, } \\
\text { D-Glucose-6-Phosphate } \\
\text { Polymers } \\
\text { Dextrin, } \\
\text { Tween 40 } \\
\text { Amides } \\
\text { Glucuronamide } \\
\text { Amines } \\
\text { Putrescine } \\
\text { Brominated chemicals } \\
\text { Bromosuccinic acid }\end{array}$ & $\begin{array}{l}\text { Carbohydrates } \\
\text { N-Acetyl } \\
\text { D-Glucosamine, } \\
\text { Adonitol, L-Arabinose, } \\
\text { D-Cellobiose, } \\
\text { D-Fructose, L-Fucose, } \\
\text { Gentiobiose, } \\
\alpha \text {-D-Lactose, } \\
\text { D-Melibiose, } \beta \text { Methyl } \\
\text { D-Glucoside, Turanose } \\
\text { Carboxylic acids } \\
\text { Acetic acid, } \\
\text { D-Galactonic acid } \\
\text { Lactone, } \\
\text { D-Galacturonic acid, } \\
\text { D-Glucosaminic acid, } \alpha \\
\text { Hydroxybutyric acid, } \alpha \\
\text { Keto butyric acid, } \alpha \\
\text { Keto Glutaric acid, } \\
\text { p-Hydroxy phenylacetic } \\
\text { acid, Malonic acid, } \\
\text { Quinic acid, Propionic } \\
\text { acid, Succinic acid } \\
\text { Amino acids } \\
\text { L-Glutamic acid, Glycyl } \\
\text { L-Glutamic acid, } \gamma \\
\text { Amino Butyric acid }\end{array}$ & $\begin{array}{l}\text { Carbohydrates } \\
\text { N-Acetyl } \\
\text { D-Glucosamine, } \\
\text { L-Arabinose, } \\
\text { Gentiobiose, } \\
\alpha \text {-D-Lactose, Lactulose, } \\
\text { Maltose, D-Melibiose, } \\
\text { Xylitol } \\
\text { Carboxylic acids } \\
\text { Acetic acid, } \\
\text { D-Galactonic acid } \\
\text { Lactone, } \\
\text { D-Galacturonic acid, } \\
\text { Itaconic acid, } \alpha \text { Keto } \\
\text { Glutaric acid, Malonic } \\
\text { acid, Succinic acid } \\
\text { Polymers } \\
\text { Tween } 80 \\
\text { Esters } \\
\text { Succinic acid mono } \\
\text { methyl ester } \\
\text { Brominated chemicals } \\
\text { Bromosuccinic acid }\end{array}$ & $\begin{array}{l}\text { Carbohydrates } \\
\text { N-Acetyl D- } \\
\text { Glucosamine, } \\
\text { Adonitol, L-Arabinose, } \\
\text { D-Cellobiose, } \\
\text { D-Galactose, } \\
\text { Gentiobiose, Lactulose, } \\
\text { D-Melibiose, } \beta \text { Methyl } \\
\text { D-Glucoside, Turanose, } \\
\text { Xylitol } \\
\text { Carboxylic acids } \\
\text { D-Glucosaminic acid, } \alpha \\
\text { Keto butyric acid, } \alpha \\
\text { Keto Glutaric acid, } \\
\text { p-Hydroxy phenylacetic } \\
\text { acid } \\
\text { Amino acids } \\
\text { Glycyl L-Glutamic acid, } \\
\text { L-Ornithine, L-Serine, } \\
\gamma \text { Amino Butyric acid } \\
\text { Phosphorylated } \\
\text { chemicals } \\
\text { D-L- } \alpha \text {-Glycerol } \\
\text { Phosphate, D-Glucose- } \\
\text { 1-Phosphate, } \\
\text { D-Glucose-6-Phosphate }\end{array}$ \\
\hline
\end{tabular}


Table 6 Number of carbon sources that were not used by microorganisms in the different treatments ("total number of substrates used) (Continued)

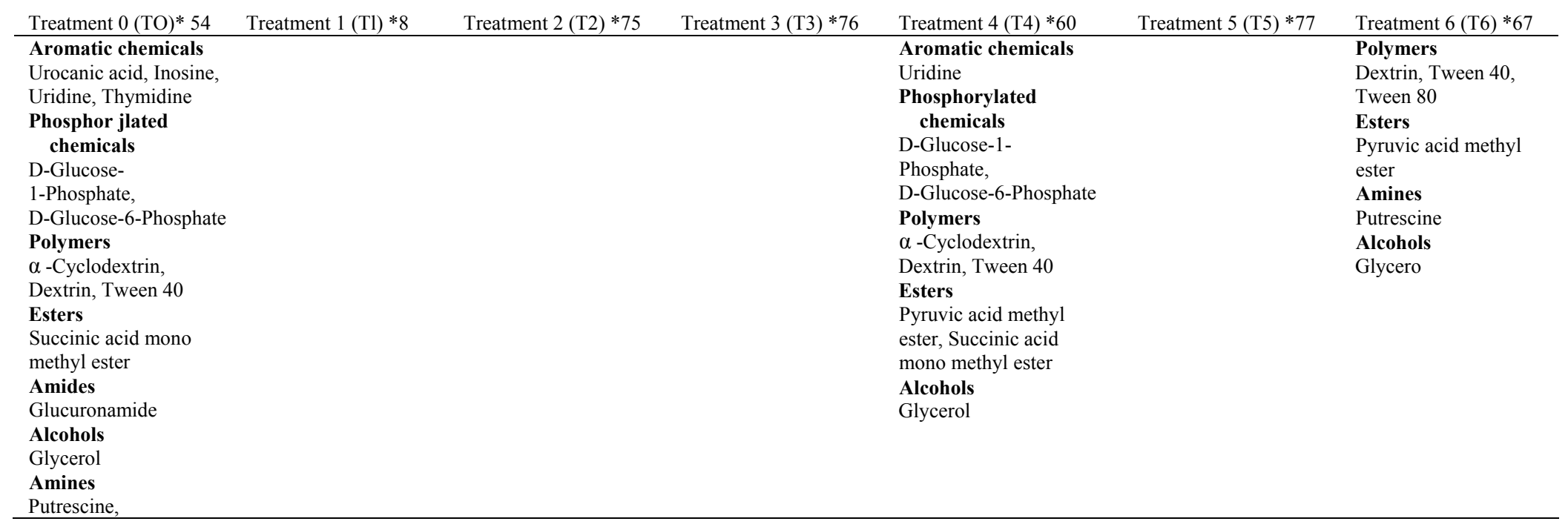


contaminated multiplanted soil with Brachiaria serrata and Eleusine corocana than to other treatments. This can be attributed to the "similarities" in metabolic diversity of the contaminated treatments caused by the presence of the stressor (PAHs).

The functional diversities of the different treatments were further evaluated using hierarchical clustering. In a dendrogram, the contaminated soils (CS, CSBS, and CSBEC) were clustered together while CSEC was clustered with the uncontaminated soils. These results were perplexing as it was expected that CSEC, a planted:contaminated soil, was going to be clustered with other contaminated soil due to presence of the stressor, which can cause significant changes in soil microbial communities (Rathbone et al., 1998). The number of Biolog substrates used by microorganisms in the planted treatments was higher compared to the nonplanted treatments. This can be attributed to the improved microbial competence brought by the presence of the plants.

In conclusion, plant-mediated dissipation of PAHs was enhanced in the multiplanted treatments compared to the monoplanted treatments. However, enhanced PAH dissipation in the multiplanted treatments compared to the monoplanted treatments did not correspond to high functional diversity, as revealed by the number of Biolog substrates used. The results suggest that multiplant rhizoremediation should be considered when evaluating remedial approaches for moderately contaminated soils. The results further strengthen the suggestion that "bioaugumentation" in moderately contaminated soils can be achieved by using multiplanted instead of monocultures to enhance the competence of the soil bacteria. However, further work is required to understand microbial diversity in multiplanted soil treatments, particularly as root exudates by one plant species may suppress or encourage the bacterial species "predominant" when each plant grows in isolation.

\section{ACKNOWLEDGEMENT}

The authors would like to thank the National Research Foundation and RCN of Norway (project 152243/730) for funding this project.

\section{REFERENCES}

Angers, D.A. and Caron, J. 1998. Plant-induced changes in soil structure: Processes and feedbacks. Biogeochem. 42, 55-72.

Aprill, W. and Sims, R.C. 1990. Evaluation of the use of prairie grasses for stimulating polycyclic aromatic hydrocarbon treatment in soil. Chemosph. 20(1-2), 253-265.

Atlas, R.M., Horowitz, A., Krichevsky, M., and Bej, A.K. 1991. Response of microbial populations to environmental disturbance. Microbial. Ecol. 22, 249-256.

Cerniglia, C.E. 1992. Biodegradation of polycyclic aromatic hydrocarbons. Biodegrad. 3, 351-368.

Cerniglia, C.E. and Heitkamp, M.A. 1989. Microbial degradation of polycyclic aromatica hydrocarbons in the aquatic environment, In: Metabolism of Polycyclic Aromatic Hydrocarbons in the Aquatic Environment, pp. 41-68 (Varanasi, U. Ed.). Boca Raton, FL: CRC.

Chen, Y.C., Banks, M.K., and Schwab, A.P. 2003. Pyrene degradation in the rhizosphere of Tall Fescue (Festuca arundinacea) and Switch grass (Panicum virgatum L.). Environmen. Sci. and Te c hnol. 37, 5778-5782.

Cunningham, S.D. and Ow, D.W. 1996. Promise and prospects of phytoremediation-Update on biotechnology. Plant Physiology. 110, 715-719.

Curl, E.A. and Truelove, B. 1986. Rhizosphere in relation to plant nutrition and growth. In: The Rhizosphere. 6. pp. 167-189. Berlin, Germany Springer-Verlag. 
Günther, T., Dornberger, U., and Fritsche, W. 1996. Effects of rye grass on biodegradation of hydrocarbons in soil. Chemosph. 33(2), 203-215.

Lee, E. and Banks, M.K. 1993. Bioremediation of petroleum contaminated soil using vegetation: A Microbial study. J. Environ. Health. A28(10), 2187-2198.

Leyval, C. and Binet, P. 1998. Effect of polyaromatic hydrocarbons in soil on arbuscular mycorrhizal plants. J. Environmen. Quality. 27, 402-407.

Maila, M.P. and Cloete, T.E. 2002. Germination of Lepidium sativum as a method to evaluate polycyclic aromatic hydrocarbons (PAHs) removal from contaminated soil. Int. Biodeterioration Biodegradation. 50, 107-113.

Muratova, A., Hübner, T., Tischer, S., Turkovskaya, O., Möder, M., and Kuschk, P. 2003. Plantrhizosphere-microflora association during phytoremediation of PAH-contaminated soil. Int. J. Phytoremed. 5(2), 137-151.

Rathbone, K., Fuchs, J., Anderson, K., Karthikeyan, R., and Nurhidayat, N. 1998. Effects of PAHs on microbial activity and diversity in freshly contaminated and weathered soils. In: Proceedings of the 1998 Conference on Hazardous Waste Research, pp. 383-402. Snowbird, UT, May 18-21.

Reilly, K.A., Banks, M.K., and Schwab, A.P. 1996. Organic chemicals in the environment: Dissipation of PAHs in the rhizosphere. J. Environ. Quality. 25, 212-219.

Rovira, A.D. 1956. Plant roots excretions in relation to the rhizosphere effect. 1. The nature of root exudates from oats and peas. Plant Soil. 47, 178-194.

Rovira, A.D. 1959. Plant roots excretions in relation to the rhizosphere effect. IV. Influence of plant species, age of plant, light, temperature, and calcium nutrition on exudation. Plant Soil. 9 , 53-64.

Saxton, A.J. and Atlas, R.M. 1977. Response of microbial populations in Arctic tundra soils to crude oil. Can. J. Microbio. 23, 1327-1333.

Schnoor, J.L., Licht, L.A., McCutcheon, S.C., Wolfe, N.L., and Carreira, L.H. 1995. Phytoremediation of organic and nutrient contaminants. Environ. Sci. Technol. 29, 318A-323A.

Walton, B.T., Guthrie, E.A., and Hoylman, A.M. 1994. Toxicant degradation in the rhizosphere. In: Bioremediation through Rhizosphere Technology, Anderson, T., and Coats, J., Eds., American Chemical Society Symposium Series, pp. 11-26.

Wollum, A.G. 1982. Cultural methods for soil microorganisms. In: Methods of Soil Analysis Part 2, (R.H. Miller and D.R. Keeney, Eds.) pp. 783-787. American Society of America, Inc., and Soil Science Society of America, Inc., Madison, WI.

Wünsche, L., Bruggemann, L., and Babel, W. 1995. Determination of substrate utilisation patterns of soil microbial communities: An approach to assess population changes after hydrocarbon pollution. FEMS Microbiol. Ecol. 17, 295-306. 